
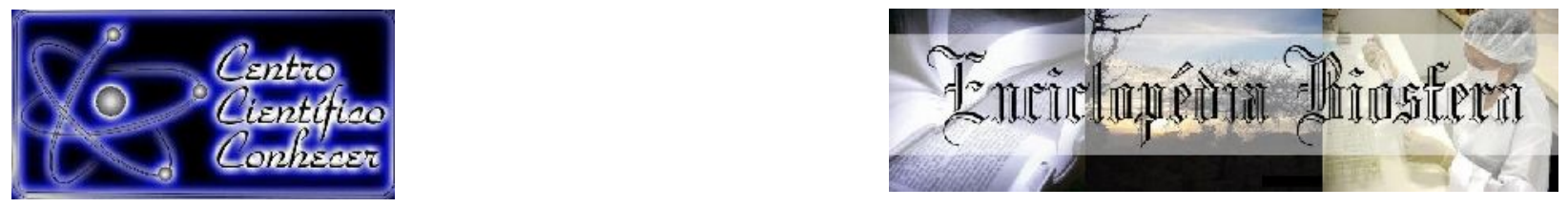

\title{
EFEITO DA ANTROPIZAÇÃO SOBRE A PRODUÇÃO DA ENZIMA XILANASE EM ACTINOBATÉRIAS
}

Juliani Barbosa de Sousa ${ }^{1}$; Ingred da Costa Lira ${ }^{2}$; Suzana Cláudia Silveira Martins ${ }^{3}$; Claudia Miranda Martins ${ }^{4}$

1.Doutoranda do Programa de Pós-Graduação em Ecologia e Recursos Naturais na Universidade Federal do Ceará - Campus do Pici, Fortaleza-CE, Brasil. julianibarbosadesousa@gmail.com

2.Discente de Agronomia na Universidade Federal do Ceará - Campus do Pici, Fortaleza-CE

3. Docente na Universidade Federal do Ceará - Campus do Pici, Fortaleza-CE, Brasil.

4. Docente na Universidade Federal do Ceará - Campus do Pici, Fortaleza-CE, Brasil.

Recebido em: 22/09/2018 - Aprovado em: 23/11/2018 - Publicado em: 03/12/2018 DOI: 10.18677/EnciBio_2018B84

\begin{abstract}
RESUMO
As actinobactérias são um grupo de bactérias filamentosas capazes de produzir metabólitos secundários de importância econômica, entre esses está a xilanase, um complexo extracelular que ocorre em micro-organismos, responsável pela degradação da hemicelulose xilana, com o exposto, este trabalho foi realizado com o objetivo de verificar a atividade xilanolítica de actinobactérias isoladas da cidade de Quixadá-CE, assim como comparar essa atividade entre uma área conservada e outra degradada. As amostras de solo foram coletadas na Fazenda Não Me Deixes, onde foram obtidas 38 cepas, sendo 19 de área antropizada e 19 de área conservada, que foram testadas para a produção de xilanase. Do total de cepas testadas, 26 apresentaram a capacidade de produzir xilanase. As cepas oriundas da área antropizada apresentaram uma maior produção da enzima. O isolado QX 7 obteve um maior índice enzimático e, portanto, potencial na produção de enzima xilanase extracelular que pode ser usada em aplicações industriais.
\end{abstract}

PALAVRAS-CHAVE: Atividade enzimática, caatinga, solo.

\section{EFFECT OF ANTROPIZATION ON THE PRODUCTION OF XYLANASE ENZYME OF ACTINOBATERIA}

\begin{abstract}
Actinobacteria are a group of filamentous bacteria capable of producing secondary metabolites of economic importance, like the xylanase, an extracellular complex that occurs in microorganisms, responsible for the degradation of xylan hemicellulose. The objective of this study was to verify the xylanolytic activity of actinobacteria isolated from the city of Quixadá-CE and compare its activity between a conserved area and a degraded area. Soil samples were collected at the "Não Me Deixes" farm,
\end{abstract}


from which 38 strains were isolated, selected and analyzed for the production of xylanase, 19 belonging to an anthropic area and 19 of a conserved area. The results showed that 26 strains had the ability to produce xylanase. The strains from the anthropic area showed the highest production of the enzyme. The QX 7 strain stood out with a higher enzymatic index and, therefore, potential in the production of extracellular xylanase enzyme that can be used in industrial applications.

KEYWORDS: Enzyme activity, caatinga, soil.

\section{INTRODUÇÃO}

As actinobactérias são um grupo de bactérias filamentosas, Gram-positivas, que desenvolvem hifas morfologicamente semelhantes às dos fungos, porém, com diâmetros menores, sendo que, fisiologicamente, se assemelham a bactérias (SULTAN et al., 2002). São capazes de produzir metabólitos secundários de importância econômica, enzimas e compostos antimicrobianos ou antifúngicos, com aplicações potenciais para biotecnologia, biofarmacêutica, uso clínico e biocontrole (LAMILLA et al., 2016).

Entre esses metabólitos importantes está a produção de xilanase, um complexo extracelular que ocorre em micro-organismos, responsável pela degradação da hemicelulose xilana (VAIJAYANTHI et al., 2016). É aplicada na conversão da xilana na agricultura e na indústria alimentícia, assim como produção de matéria-prima para combustíveis e produtos químicos. Esta enzima também pode ser usada como bio-branqueamento na indústria de papel, purificação, e aprimoramento do aroma de suco de uva, além de melhorar o aroma e a qualidade do pão e ração animal (SIPRIYADI et al., 2016).

Nos últimos anos ocorreu um aumento no relato de organismos capazes de produzir a enzima xilanase (CHAUHAN et al., 2015; GUPTA et al., 2015), assim como um aumento nos relatos de actinobactérias provenientes do semiárido capazes de produzir enzimas extracelulares (LOPES et al., 2018; SILVA et al., 2015). Esses ambientes semiáridos caracterizam-se por uma heterogeneidade na vegetação, clima e condições edáficas, amplitudes térmicas elevadas e solos com pouca umidade e oligotróficos (BRESSIANI et al., 2015), essas características produzem habitats distintos e organismos adaptados a estresses abióticos. Este trabalho foi realizado com o objetivo de verificar a atividade xilanolítica de actinobactérias isoladas da cidade de Quixadá-CE, assim como comparar essa atividade entre uma área conservada e uma área degradada.

\section{MATERIAL E MÉTODOS}

\section{Área de estudo}

As coletas de solo foram realizadas na Fazenda Não Me Deixes, que está localizada em Quixadá, Ceará, onde, no ano de 1998, teve 300 ha reconhecidos como Reserva Particular do Patrimônio Natural (RPPN) pelo Instituto Brasileiro do Meio Ambiente e dos Recursos Naturais Renováveis (IBAMA), a propriedade tem 929 ha com as coordenadas geográficas 449'34'S, 3858'9'W e $210 \mathrm{~m}$ de altitude. As coletas foram feitas em duas áreas: na unidade de conservação e em uma área de 1 hectare, antropizada, pertencente a Fazenda Não Me Deixes, mas que está fora da RPPN. A região possui um clima Tropical Quente Semiárido, com pluviosidade média de $732,8 \mathrm{~mm}$, concentrada nos meses de fevereiro a abril, e temperatura média de $26,6^{\circ}$ (FUNCEME, 2017). 


\section{Análise do solo}

Para caracterização química do solo foram realizadas as análises: $\mathrm{pH}$ em $\mathrm{H}_{2} \mathrm{O}$ $(1: 2,5)$ por potenciometria; acidez potencial $(\mathrm{H}+\mathrm{Al})$, extraída com acetato de cálcio tamponado a pH 7,0 e determinada por titulometria; cálcio $\left(\mathrm{Ca}^{2+}\right)$ e magnésio $\left(\mathrm{Mg}^{2+}\right)$, extraídos com solução de $\mathrm{KCl} 1 \mathrm{M}$ e determinados por espectrometria de absorção atômica; alumínio trocável $\left(\mathrm{Al}^{3+}\right)$, extraído com solução $\mathrm{KCl} 1 \mathrm{M}$ e determinado por titulometria. Fósforo $(\mathrm{P})$, sódio $\left(\mathrm{Na}^{+}\right)$e potássio $(\mathrm{K}+)$ foram extraídos com solução Mehlich 1, com o $\mathrm{P}$ determinado por colorimetria e $0 \mathrm{~K}^{+}$e $\mathrm{Na}^{+}$por fotometria de chama (TEIXEIRA et al., 2017).

\section{Actinobactérias}

A partir das amostras de solo foram isoladas 38 cepas de actinobactérias denominadas em código (QX-número), 19 cepas são provenientes da área antropizada e 19 da área conservada. As cepas estão armazenadas em tubos inclinados no meio Caseína Dextrose Ágar (CDA) (KUSTER; WILLIAMS, 1964; ARIFUZZAMAN et al., 2010) com óleo mineral, a temperatura ambiente, no Laboratório de Microbiologia Ambiental (LAMAB) do Departamento de Biologia da Universidade Federal do Ceará, fazendo parte da coleção de actinobactérias oriundas do semiárido nordestino.

\section{Produção de xilanase}

A produção de xilanase foi feita conforme Kumar et al. (2012) modificada. As actinobactérias foram inoculadas em quatro spots no meio Agar-xilanase $\left(\mathrm{g} \mathrm{L}^{-1}\right)$ : xilana (1), $\mathrm{NaNO}_{3}(0,5), \mathrm{K}_{2} \mathrm{HPO}_{4}(1), \mathrm{MgSO}_{4} .7 \mathrm{H}_{2} \mathrm{O}(0,5), \mathrm{FeSO}_{4} .7 \mathrm{H}_{2} \mathrm{O}(0,01)$, extrato de levedura (1), ágar (15) e pH 6,5. Posteriormente, as culturas foram incubadas em câmara de crescimento tipo B.O.D., a $28^{\circ} \mathrm{C}$ por 10 dias. Após a incubação, foram adicionados $10 \mathrm{~mL}$ da solução de vermelho congo a 0,5\% em cada placa, deixandose agir por 15 minutos sob temperatura ambiente, o excesso da solução foi drenado e $10 \mathrm{~mL}$ de solução de $\mathrm{NaCl}(2 \mathrm{M})$ foram adicionados em cada placa, deixando-se agir por 30 minutos a temperatura ambiente, após esse tempo foi observada a presença ou ausência das zonas de hidrólise ao redor da colônia e medido, com a ajuda de um paquímetro, o tamanho do halo e da colônia.

\section{Determinação do perfil enzimático}

Foram calculados os índices enzimáticos (IE) da amilase, celulase e xilanase utilizando a equação (HANKIN; ANAGNOSTAKIS, 1977): IE = Dh/Dc, onde, Dh é o diâmetro em $\mathrm{mm}$ do halo de hidrólise e Dc o diâmetro em $\mathrm{mm}$ do halo da colônia. A classificação das cepas foi feita como fracamente produtoras $(1 \leq \mathrm{IE}<1,5)$, moderadamente produtoras $(1,5 \leq \mathrm{IE}<2)$ e fortemente produtoras $(\mathrm{IE} \geq 2)$.

\section{Análises estatísticas}

As medidas de cada IE foram obtidas em milímetros e analisadas utilizando o programa estatístico SPSS (2004). Inicialmente foi realizado o teste de alfa de Cronbach para verificar a consistência dos dados, após, foi analisada a normalidade dos dados através do teste de Shapiro-Wilk, e a homogeneidade das variâncias através do teste de Levene, logo após as médias dos índices enzimáticos foram submetidas a uma ANOVA (análise de variância) para comparar os resultados das 
cepas e para comparar os resultados entre as áreas foi utilizado um teste t para duas médias.

\section{RESULTADOS E DISCUSSÃO}

Amostras de solo coletadas na zona de estudo nas duas áreas diferiram em suas propriedades químicas (Tabela 1 ). $\mathrm{O} \mathrm{pH}$ do solo variou de 5,17 na área antropizada a 4,5 na área conservada. Já a capacidade de troca de cátions (CTC) e a quantidade de fósforo $(P)$ foi menor na área antropizada, enquanto que a porcentagem de saturação por bases (V) foi maior. A área antropizada apresenta alta saturação por bases (V\% > 50), entretanto, a soma de bases (S) e CTC são baixas. Em relação à fertilidade do solo, a área conservada possui maior concentração de nutrientes para as plantas e organismos, expressa por uma maior soma de bases e CTC, sua limitação está na acidez (maior $\mathrm{H}+\mathrm{Al}$ ).

TABELA 1: Caracterização química do solo coletado na Fazenda Não Me Deixes, localizada no município de Quixadá-CE, área antropizada e área conservada.

\begin{tabular}{|c|c|c|c|c|c|c|c|c|c|c|c|}
\hline \multirow{3}{*}{ Área } & \multirow{3}{*}{$\begin{array}{c}\text { pH Água } \\
1: 2,5\end{array}$} & \multicolumn{7}{|c|}{ Complexo Sortivo } & \multirow{2}{*}{$\mathrm{CTC}^{2}$} & \multirow{2}{*}{$\mathrm{V}^{3}$} & \multirow{2}{*}{$\mathrm{P}$} \\
\hline & & $\mathrm{Ca}^{2+}$ & $\mathrm{Mg}^{2+}$ & $\mathrm{K}^{+}$ & $\mathrm{Na}^{+}$ & $\mathrm{S}^{1}$ & $\mathrm{Al}^{3+}$ & $\mathrm{H}+\mathrm{Al}^{3^{+}}$ & & & \\
\hline & & & & & $------\mathrm{cr}$ & $\mathrm{nol}_{\mathrm{c}} \mathrm{kg}^{-}$ & & & - & $----\%--$ & mg.kg \\
\hline Conservada & 4,5 & 2,4 & 0,6 & 0,33 & 0,12 & 10,86 & 0,1 & 7,4 & 10,86 & 31,86 & 8,98 \\
\hline Antropizada & 5,17 & 1,81 & 0,51 & 0,19 & 0 & 3,015 & 0 & 1,21 & 3,71 & 66,65 & 3,48 \\
\hline
\end{tabular}

A zona mais clara ao redor das colônias, correspondente ao halo indicador da degradação da xilana (Figura 1), foi observada em 26 cepas, ou seja, 68\% das actinobactérias estudadas.

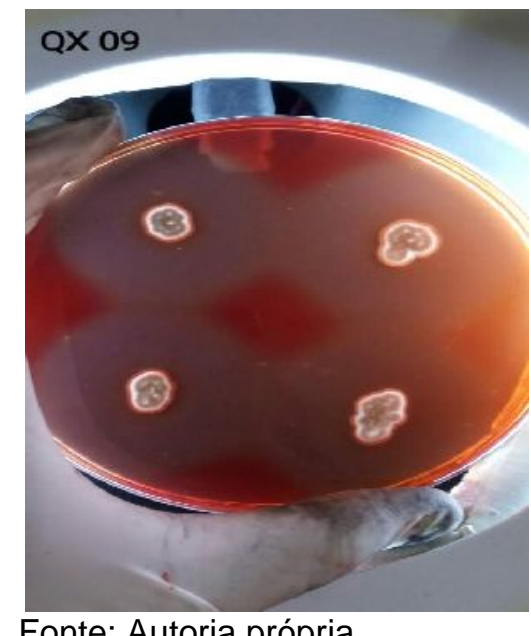

Fonte: Autoria própria.

FIGURA 1: Halo indicador da degradação da xilana por cepas de actinobactérias isoladas do solo da Fazenda Não Me Deixes, localizada no município de Quixadá-CE, em função do índice enzimático (IE). 
Observa-se que os diâmetros das zonas de inibição entre as cepas de actinobactérias variaram de $8,76 \pm 0,15 \mathrm{~mm}(\mathrm{QX} \mathrm{10})$ a $39,62 \pm 0,82 \mathrm{~mm}$ (QX 02) (Tabela 2). Nas cepas de actinobactérias QX 16, QX 21, QX 22, QX 25, QX 30, QX 45, QX 48, QX 53, QX 63, QX 65, QX 66, QX 76, (32\%), não foi observada a formação de halo enzimático de degradação, indicando que estas não apresentam atividade xilanolítica.

TABELA 2: Índice enzimático (IE) de xilanase de cepas de actinobactérias isoladas da Fazenda Não Me Deixes, localizada no município de Quixadá-CE. Os resultados correspondem à média de quatro repetições, com o erro padrão.

\begin{tabular}{cccc}
\hline Cepas & Dc $(\mathbf{m m})$ & Dh $(\mathbf{m m})$ & IE \\
\hline QX 1 & $6,53 \pm 0,65$ & $34,56 \pm 0,64$ & 2,34 \\
QX 2 & $7,23 \pm 0,32$ & $39,62 \pm 0,82$ & 2,77 \\
QX 5 & $12,96 \pm 0,23$ & $32,61 \pm 0,55$ & 1,50 \\
QX 6 & $12,40 \pm 0,39$ & $17,46 \pm 0,76$ & 1,04 \\
QX 7 & $6,26 \pm 0,44$ & $37,23 \pm 1,39$ & 3,02 \\
QX 9 & $11,19 \pm 0,61$ & $37,03 \pm 0,58$ & 1,65 \\
QX 10 & $5,80 \pm 0,17$ & $8,76 \pm 0,15$ & 1,13 \\
QX 12 & $9,64 \pm 0,28$ & $27,98 \pm 1,46$ & 1,42 \\
QX 13 & $9,43 \pm 0,49$ & $34,66 \pm 0,31$ & 2,16 \\
QX 14 & $10,76 \pm 1,18$ & $26,12 \pm 3,43$ & 1,59 \\
QX 15 & $11,91 \pm 0,61$ & $31,96 \pm 1,16$ & 1,38 \\
QX 17 & $14,41 \pm 0,58$ & $32,26 \pm 1,04$ & 1,29 \\
QX 24 & $13,70 \pm 0,76$ & $37,36 \pm 1,17$ & 1,45 \\
QX 28 & $8,14 \pm 0,48$ & $36,43 \pm 1,21$ & 2,41 \\
QX 31 & $7,65 \pm 0,21$ & $36,68 \pm 1,12$ & 2,54 \\
QX 32 & $9,61 \pm 0,25$ & $24,10 \pm 1,35$ & 1,35 \\
QX 55 & $9,79 \pm 0,44$ & $23,97 \pm 0,70$ & 1,39 \\
QX 56 & $10,61 \pm 0,14$ & $36,14 \pm 2,09$ & 2,01 \\
QX 57 & $13,18 \pm 0,56$ & $36,52 \pm 0,66$ & 1,65 \\
QX 61 & $14,47 \pm 0,75$ & $32,15 \pm 1,32$ & 1,45 \\
QX 62 & $11,14 \pm 0,65$ & $33,32 \pm 0,93$ & 1,60 \\
QX 64 & $12,68 \pm 0,43$ & $24,40 \pm 0,81$ & 1,27 \\
QX 68 & $7,86 \pm 0,69$ & $32,57 \pm 0,81$ & 2,54 \\
QX 71 & $9,95 \pm 0,37$ & $37,97 \pm 1,59$ & 1,97 \\
QX 73 & $11,95 \pm 1,12$ & $34,30 \pm 1,02$ & 1,68 \\
QX 75 & $9,57 \pm 0,45$ & $35,01 \pm 1,20$ & 1,81 \\
\hline Dc diâmetro da colônia (mm); Dh $=$ diâmetro do halo (mm); IE $=$ \\
índice enzimático. & & &
\end{tabular}

A produção de xilanase é um fator importante na reciclagem de resíduos agrícolas já que é o segundo polissacarídeo natural mais importante, geralmente encontrada na parede celular, entre a lignina e a celulose, nas células de plantas (MOHAMED et al., 2017). 
Numa tentativa de comparar o potencial enzimático das cepas de actinobactérias neste estudo, foi estabelecido um índice enzimático, conforme Florêncio et al. (2012) onde, valores maiores que 1,5 indicam que as cepas possuem potencial como produtores de enzimas extracelulares. As cepas do presente estudo apresentaram IE variando de 1,04 a 3,02.

$O$ teste $t$ foi realizado entre os índices enzimáticos das cepas, que apresentaram diferença estatística entre si, onde, as cepas QX 2, QX 7, QX 28, QX 31 e QX 68, com os maiores valores de índice enzimático, se destacaram em relação as demais.

Esses índices estão de acordo com o encontrado na literatura, Omar et al. (2017), isolaram cepas de um manguezal, na Malásia, que apresentaram um índice enzimático máximo de 3,35, valor próximo dos encontrados nesse trabalho, assim como Sipriyadi et al. (2016) que obtiveram 8 cepas, das 35 isoladas do solo de uma floresta, na Indonésia, que produziram xilanase e um IE máximo de 3,25.

Sanjivkumar et al. (2017), avaliaram 40 cepas oriundas de um manguezal na Índia, das quais apenas 4 cepas eram capazes de degradar a xilana, as quais apresentaram uma zona hidrolítica máxima de $29 \mathrm{~mm}$ de diâmetro, enquanto que o halo máximo encontrado nesse trabalho foi de $39 \mathrm{~mm}$ de diâmetro.

A análise estatística apresentou um alfa de Cronbach no valor de 0,823. A análise de variância mostrou diferença entre os índices enzimáticos analisadas entre os grupos (Figura 2), a área antropizada apresentou um maior número de estirpes produtoras da enzima, $78 \%$ das cepas apresentaram halo de inibição comparado com $57 \%$ das cepas provenientes da área conservada. Também há diferença estatística entre as cepas fortemente produtoras, onde a área antrópica apresentou uma maior porcentagem (63\%), QX 1, QX 2, QX 5, QX 7, QX 9, QX 12, QX 61, QX 62, QX 68, QX 71, QX 73, QX 75, com as estirpes do que a área conservada (57\%), QX 13, QX 14, QX 15, QX 17, QX 24, QX 28, QX 31, QX 32, QX 55, QX 56, QX 57.

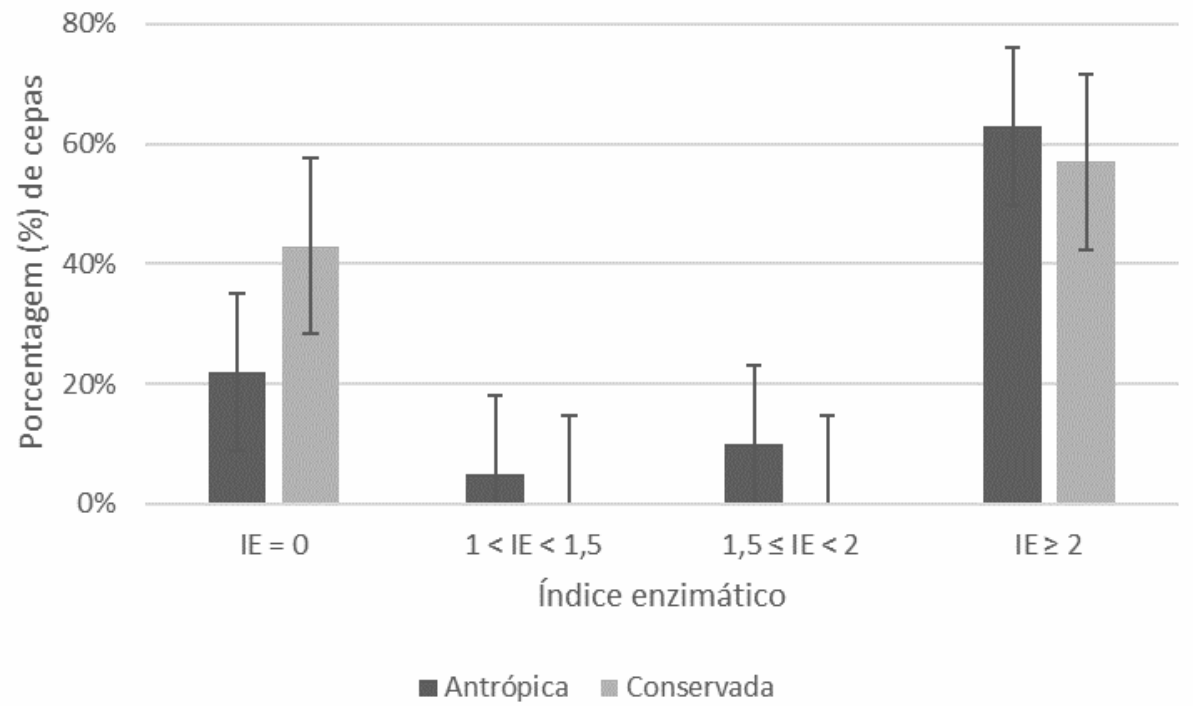

FIGURA 2: Classificação da intensidade de produção de xilanase das cepas de actinobactérias isoladas do solo da Fazenda Não Me Deixes, localizada no município de Quixadá-CE, em função do índice enzimático (IE). 
Essas diferenças entre as áreas podem ser explicadas pelas variações nas características do solo das duas áreas, Manzoni et al. (2014) relataram que o crescimento microbiano é influenciado pelas características de seu ambiente natural, que depende da química da matéria orgânica, umidade do solo, temperatura do solo e acesso físico da (s) enzima (s) ao (s) substrato (s).

Já Ramanjaneyulu et al. (2016), afirmaram que as características físicoquímicas do solo podem influenciar na produção de xilanase por micro-organismos, fungos, bactérias e actinobactérias, onde a maior concentração desses organismos ocorreu em um solo com pH 5,1, condizente com os resultados encontrados, onde a área conservada, que possui um pH mais ácido houve uma menor concentração de organismos produtores da enzima xilanase.

\section{CONCLUSÃO}

Pode-se concluir que 26 cepas de actinobactérias possuem a capacidade de produção de xilanase extracelular, com destaque para a cepa QX 7 a qual pode apresentar potencial em aplicações biotecnológicas.

\section{AGRADECIMENTOS}

O presente trabalho foi realizado com apoio da Coordenação de Aperfeiçoamento de Pessoal de Nível Superior-Brasil (CAPES)-Código de Financiamento 001.

\section{REFERÊNCIAS}

ARIFUZZAMAN, M., KHATUN, M. R., RAHMAN, H. Isolation and screening of actinomycetes from Sundarbans soil for antibacterial activity. African Journal of Biotechnology, v.9, n.29, p.4615-4619, 2010. Disponível em: < https://www.ajol.info/index.php/ajb/article/view/82733/72871 >.

BRESSIANI, D. A., GASSMAN, P. W., FERNANDES, J. G., GARBOSSA, L. H. P., SRINIVASAN, R., et al. Review of Soil and Water Assessment Tool (SWAT) applications in Brazil: Challenges and prospects. International Journal of Agricultural and Biological Enginering, v.8, n.3, p.9-35, 2015. Disponível em: < https://ijabe.org/index.php/ijabe/article/view/1765>

doi: 10.3965/j.ijabe.20150803.1765.

CHAUHAN, S., SETH, C. A.; SETH, A. Bioprospecting thermophilic microorganisms from hot springs of western himalyas for xylanase production and its statistical optimization by using response surface methodology. Journal of Pure and Applied Microbiology, v. 9, n. 2, p. 1417-1428, 2015. Disponível em: < https://www.researchgate.net/profile/Amit_Seth/publication/283819292_Bioprospecti ng_thermophilic_microorganisms_from_hot_springs_of_western_himalyas_for_xylan ase_production_and_its_statistical_optimization_by_using_response_surface_metho dology/links/5947b0bdaca27242cda59380/Bioprospecting-thermophilicmicroorganisms-from-hot-springs-of-western-himalyas-for-xylanase-production-andits-statistical-optimization-by-using-response-surface-methodology.pdf>

FLORENCIO, C., COURI, S., FARINAS, C. Correlation between agar plate screening and solid-state fermentation for the prediction of cellulase production by Trichoderma strains. Enzyme Research. v.2012, 2012. Disponível: < Correlation between Agar 
Plate Screening and Solid-State Fermentation for the Prediction of Cellulase Production by Trichoderma Strains> doi: 10.1155/2012/793708.

FUNCEME: Fundação Cearense de Meteorologia e Recursos Hídricos. Dados dos postos pluviométricos do Ceará, 2017. Disponível em: <http://www.funceme.br/app/calendario/produto/municipios/maxima/diario?data=hoje $>$ Acesso em: 15 fev. 2017.

GUPTA, V., GARG, S., CAPALASH, N., GUPTA, N., SHARMA, P. Production of thermo-alkali-stable laccase and xylanase by co-culturing of Bacillus sp. and $B$. halodurans for biobleaching of kraft pulp and deinking of waste paper. Bioprocess and Biosystems Engineering, v.38, n.5, p.947-956, 2015. Disponível em: <http://sci-hub.tw/10.1007/s00449-014-1340-0> doi: 10.1007/s00449-014-1340-0.

HANKIN, L., ANAGNOSTAKIS, S. L. Solid media containing carboxymethylcellulose to detect cellulose activity of microorganisms. Journal of General Microbiology, v.98, p.109-115, $1977 . \quad$ Disponível em: https://www.ncbi.nlm.nih.gov/pubmed/401863> doi: 10.1099/00221287-98-1-109.

KUMAR, V., BHARTI, A., NEGI, Y. K., GUSAIN, O., PANDEY, P., et al. Screening of actinomycetes from earthworm castings for their antimicrobial activity and industrial enzymes. Brazilian Journal of Microbiology, v.43, n.1, p.205-214, 2012. Disponível

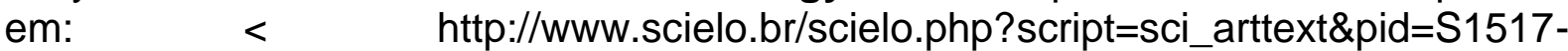
83822012000100022> doi: 10.1590/S1517-83822012000100022.

KUSTER, E.; WILLIAMS, S.T. Selective media for the isolation of Streptomycetes. Nature, v. 202, p.928-929, 1964. Disponível em: <https://www.nature.com/articles/202928a0.pdf>.

LAMILLA, C., PAVEZ, M., SANTOS, A., HERMOSILLA, A., LLANQUINAO, V., et al. Bioprospecting for extracellular enzymes from culturable Actinobacteria from the South Shetland Islands, Antarctica. Polar Biology, v. 40, n. 3, p. 719-726, 2016. Disponível em: < https://link.springer.com/article/10.1007/s00300-016-1977-z> doi: 10.1007/s00300-016-1977-z.

LOPES, J. B. A. C., SilvA, V. M. A., CAVAlCANTE, F. G., MARTinS, S. C. S., MARTINS, C. M. Produção de enzimas hidrolíticas extracelulares por actinobactérias oriundas do solo e serrapilheira de região semiárida. Enciclopédia Biosfera, v. 15, n. 27, p. 35-50, 2018. Disponível em: < http://www.conhecer.org.br/enciclop/2018a/biol/producao.pdf> doi: 10.18677/EnciBio_2018A93.

MANZONI, S., SCHAEFFER, S. M., KATUL, G., PORPORATO, A., SCHIMEL, J. P. A theoretical analysis of microbial eco-physiological and diffusion limitations to carbon cycling in drying soils. Soil Biology and Biochemistry, v.73, p.69-83, 2014. Disponível em: https://www.sciencedirect.com/science/article/pii/S0038071714000613> doi: 10.1016/j.soilbio.2014.02.008 
MOHAMED, A. H., YOUSEIF, S. H., ABD EL-MAGEED, F. H., HEIKAL, N. Z., MOUSSA, T. A., et al. Production of cellulase, exoglucanase and xylanase by different microorganisms cultivated on agricultural wastes. Research Journal of Pharmaceutical Biological and Chemical Sciences, v.8, n.4, p.435-452, 2017. Disponível em:

https://www.researchgate.net/publication/318471129_Production_of_cellulase_exogl ucanase_and_xylanase_by_different_microorganisms_cultivated_on_agricultural_wa stes>

OMAR, S. M., FAROUK, N. M., MALEK, N. A., ABIDIN, Z. A. Z. Verrucosispora sp. K2-04, Potential Xylanase Producer from Kuantan Mangrove Forest Sediment. International Journal of Food Engineering, v.3, n.2, 2017. Disponível em: < http://www.ijfe.org/uploadfile/2017/1227/20171227063157336.pdf> doi: 10.18178/ijfe.3.2.165-168.

RAMANJANEYULU, G., RAMYA, A., KUMARI, B. S., KUMAR, K. D., REDDY, B. R. Xylanase-producing microflora in Eastern Ghats of Andhra Pradesh, India. Journal of Forestry Research, v.28, n.2, p.291-298, 2016. Disponível em: < https://link.springer.com/article/10.1007/s11676-016-0305-3> doi: 10.1007/s11676016-0305-3.

SANJIVKUMAR, M., SILAMBARASAN, T., PALAVESAM, A., IMMANUEL, G. Biosynthesis, purification and characterization of $\beta-1,4$-xylanase from a novel mangrove associated actinobacterium Streptomyces olivaceus (MSU3) and its applications. Protein Expression and Purification, v.130, p.1-12, 2017. Disponível em: < https://www.ncbi.nlm.nih.gov/pubmed/27693622> doi: 10.1016/j.pep.2016.09.017.

SILVA, V. M.; MARTINS, C. M., MARTINS, S. C. S. Atividade celulolítica de actinobactérias de região semiárida do Ceará. Enciclopédia Biosfera, v. 11, n. 21, p. 2026-2036, 2015. Disponivel em: <http://www.conhecer.org.br/enciclop/2015b/biologicas/atividade\%20celulolitica.pdf>.

SIPRIYADI, S., LESTARI, Y., WAHYUDI, A., MERYANDINI, A. Exploration of potential actinomycetes from CIFOR forest origin as antimicrobial, antifungus, and producing extracellular xylanase. Biosaintifika: Journal of Biology \& Biology Education. $\quad$ v.8. $\quad$ n.94. 2016. Disponível em: < https://www.researchgate.net/publication/301708606_Exploration_of_Potential_Actin omycetes_from_CIFOR_Forest_Origin_as_Antimicrobial_Antifungus_and_Producing Extracellular_Xylanase> doi:10.15294/biosaintifika.v8i1.5052.

SULTAN, M. Z.; KHATUNE, N. A.; SATHI, Z. S.; BHUIYAN, S. A. M. D.; SADIK, G. M.; CHOUDURY, M. A.; GAFUR, M. A.; RAHMAN, A. A. M. D. In vitro antibacterial activity of an active metabolite isolated from Streptomyces species. Biotechnology, v.1, n.2/4, p.100-106, 2002. <Disponível em: https://scialert.net/abstract/?doi=biotech.2002.100.106> doi: 10.3923/biotech.2002.100.106. 
TEIXEIRA, P. C., DONAGEMMA, G. K., FONTANA, A., TEIXEIRA, W. G. Manual de métodos de análise de solo. Embrapa Solos-Livro técnico. Rio de Janeiro, INFOTECA-E. 2017.

VAIJAYANTHI, G., VIJAYAKUMAR, R., DHANASEKARAN, D. Actinobacteria-a biofactory of novel enzymes. In: DHANASEKARAN, D. Actinobacteria-Basics and Biotechnological Applications. London: InTech, 2016. Disponível em: < https://www.intechopen.com/books/actinobacteria-basics-and-biotechnologicalapplications/actinobacteria-a-biofactory-of-novel-enzymes> doi: 10.5772/61436. 